Elsevier required licence: (C) <2018>. This manuscript version is made available under the CC-BY-NC-ND 4.0 license http://creativecommons.org/licenses/by-nc-nd/4.0/ 


\section{Resource recovery from wastewater by anaerobic membrane bioreactors: Opportunities and challenges}

\section{Revised manuscript submitted to Bioresource Technology}

August 2018

Xiaoye Song ${ }^{\text {a }}$, Wenhai Luo ${ }^{\text {b }}$, Faisal I. Hai ${ }^{\text {a }}$, William E. Price ${ }^{c}$, Wenshan Guo ${ }^{\text {d }}$, Hao H. Ngo ${ }^{d}$, Long D. Nghiem

${ }^{a}$ Strategic Water Infrastructure Laboratory, School of Civil Mining and Environmental Engineering, University of Wollongong, Wollongong, NSW 2522,

\section{Australia}

${ }^{b}$ Beijing Key Laboratory of Farmland Soil Pollution Prevention and Remediation, College of Resources and Environmental Sciences, China Agricultural University, Beijing, 100193, China

c Strategic Water Infrastructure Laboratory, School of Chemistry, University of Wollongong, Wollongong, NSW 2522, Australia

${ }^{d}$ Centre for Technology in Water and Wastewater, University of Technology Sydney, Ultimo, NSW 2007, Australia

\footnotetext{
*Corresponding author: duclong.nghiem@uts.edu.au; Ph: +61 295142625.
} 


\section{Abstract}

This review critically discusses the potential of anaerobic membrane bioreactor (AnMBR) to serve as the core technology for simultaneous recovery of clean water, energy, and nutrient from wastewater. The potential is significant as AnMBR treatment can remove a board range of trace organic contaminants relevant to water reuse, convert organics in wastewater to biogas for subsequent energy production, and liberate nutrients to soluble forms (e.g. ammonia and phosphorus) for subsequent recovery for fertilizer production. Yet, there remain several significant challenges to the further development of AnMBR. These challenges evolve around the dilute nature of municipal wastewater, which entails the need for pre-concentrating wastewater prior to AnMBR, and hence, issues related to salinity build-up, accumulation of substances, membrane fouling, and membrane stability. Strategies to address these challenges are proposed and discussed. A road map for further research is also provided to guide future AnMBR development toward resource recovery.

Keyword: Anaerobic membrane bioreactor (AnMBR); Wastewater treatment; Resource recovery; Biogas; Water reuse.

\section{Introduction}

In a paradigm shift towards the circular economy, wastewater can no longer be viewed as the culprit of environmental pollution but rather a source of valuable resources, including clean water, renewable energy and nutrients. The economic value of key resources in wastewater can help to offset the cost of wastewater treatment (Burn et al., 2014). Indeed, reclaimed water has been considered as an alternative source to augment clean water supply and address issues caused by water shortage (Shannon et al., 2008). Energy can be extracted from the organic content in wastewater by anaerobic treatment to produce biogas, which is a renewable fuel. Nutrients in wastewater can also be recovered to produce fertilizers for sustainable agriculture production, particularly given the finite availability of phosphorus from mining (Koppelaar \& Weikard, 2013). Recent interest in these resources has spurred 
new research aiming to convert wastewater treatment plants into resource recovery facilities.

Nutrient recovery from wastewater can also reduce the maintenance cost of wastewater treatment facilities and avoid environmental impacts. During wastewater treatment, phosphate and ammonium (which are abundant in wastewater) can react with magnesium to form crystalline precipitate, known as struvite $\left(\mathrm{MgNH}_{4} \mathrm{PO}_{4} \cdot 6 \mathrm{H}_{2} \mathrm{O}\right)$, causing blockage and scaling of plant equipment (Doyle et al., 2002). Moreover, both nitrogen and phosphorus are important contaminants that can result in eutrophication of natural waterways if they are discharged to the environment.

Membrane bioreactor (MBR) has been deployed at an increasing speed to advance wastewater treatment and reuse on a global scale (Hai et al., 2014). MBR is an integration of membrane filtration with conventional activated sludge (CAS) treatment. Compared to CAS treatment, MBR exhibits several advantages, including higher effluent quality, smaller footprint, as well as easier operation and management (Judd, 2016). Indeed, MBR is more effective for the removal of trace organic contaminants (TrOCs) than CAS treatment for advanced water reuse (Luo et al., 2014). TrOCs occur ubiquitously in municipal wastewater and are of particular concern to water reuse. It is noteworthy MBR is energy-intensive since aeration is necessary for the growth and activity of activated sludge. Furthermore, energy and nutrients in wastewater are dissipated as released gases (e.g. carbon dioxide and nitrogen gas) in MBR treatment.

An alternative MBR configuration, namely anaerobic MBR or AnMBR, has also been explored for energy neutral wastewater treatment (Gao et al., 2008; Verstraete et al., 2009). AnMBR integrates anaerobic digestion treatment with membrane filtration. During AnMBR treatment, organic substances in wastewater are biologically converted to methane-rich biogas. The produced biogas can offset the energy demand for wastewater treatment (McCarty et al., 2011). Since anaerobic treatment converts nutrients to chemically available forms (e.g. ammonia and phosphate), AnMBR can also facilitate nutrient recovery via subsequent precipitation. Nevertheless, there 
remain several significant challenges in the development of AnMBR for resource recovery from wastewater, particularly municipal wastewater. These include low organic and nutrient contents in municipal wastewater as well as issues associated with salinity build-up, membrane stability, membrane fouling, and the occurrence of inhibitory substances.

In this paper, the performance of AnMBR for wastewater treatment and resource recovery is critically reviewed. Several key challenges to the further development of AnMBR are delineated. Potential strategies to address these challenges are proposed. This review paper provides important insight to the development of AnMBR for the management of water, energy, and nutrients.

\section{Fundamentals and configurations of anaerobic membrane bioreactor}

\subsection{Fundamentals of anaerobic membrane bioreactor}

AnMBR differs intrinsically from aerobic MBR in terms of the biological component. The anaerobic biological process involves four integrated stages, namely hydrolysis, acidogenesis, acetogenesis, and methanogenesis. Degradation of organic matter and their conversion to biogas depend on the symbiotic relationship among the different groups of microorganisms (e.g. fermentative bacteria, syntrophic acetogens, homoacetogens, hydrogenetrophic methanogens and aceticlastic methanogens) (Chen et al., 2016). Of these microorganism groups, methanogens play arguably the most important role for biogas production by converting intermediate products from previous stages to methane gas. However, methanogens are slow-growing microorganisms and can be easily washed out from conventional anaerobic bioreactors. By integrating membrane separation processes, commonly including microfiltration (MF) and ultrafiltration (UF), the hydraulic retention time (HRT) can be decoupled from sludge retention time (SRT). Thus, AnMBR can produce more biogas than conventional anaerobic treatment (Liao et al., 2006).

In many aspects (e.g. energy consumption, contaminant removal efficiency, and volume throughput), AnMBR differs considerably from aerobic MBR (Table 1). Since 
aeration is not required, AnMBR has a significantly lower energy input to the bioreactor compared to aerobic MBR. In addition, the energy footprint of AnMBR can be offset by produced biogas (Smith et al., 2012). Nevertheless, Martin et al. (2011) reported that the energy demand in submerged AnMBR varies considerably from 0.03 to $5.7 \mathrm{kWh} / \mathrm{m}^{3}$ due to different energy requirements for gas sparging to control membrane fouling. Indeed, AnMBR is usually operated at high biomass concentration as well as long SRT and HRT to treat complex wastewater (Skouteris et al., 2012), resulting in more severe membrane fouling in comparison with aerobic MBR. As such, the reported flux of AnMBR is commonly in the range between 5 and $12 \mathrm{~L} / \mathrm{m}^{2} \mathrm{~h}$, which is considerably lower than the flux of $20-30 \mathrm{~L} / \mathrm{m}^{2} \mathrm{~h}$ typically for full-scale aerobic MBR (Wang et al., 2018). Without oxygen as an electron acceptor, anaerobic digesters release electrons onto methane $\left(\mathrm{CH}_{4}\right)$ rather than using them for microbial growth. Thus, AnMBR produces less sludge than aerobic MBR (Liao et al., 2006). Since anaerobic degradation is a slow process, AnMBR has a lower contaminant removal efficiency and volume throughput (i.e. treatment capability) than aerobic MBR. 


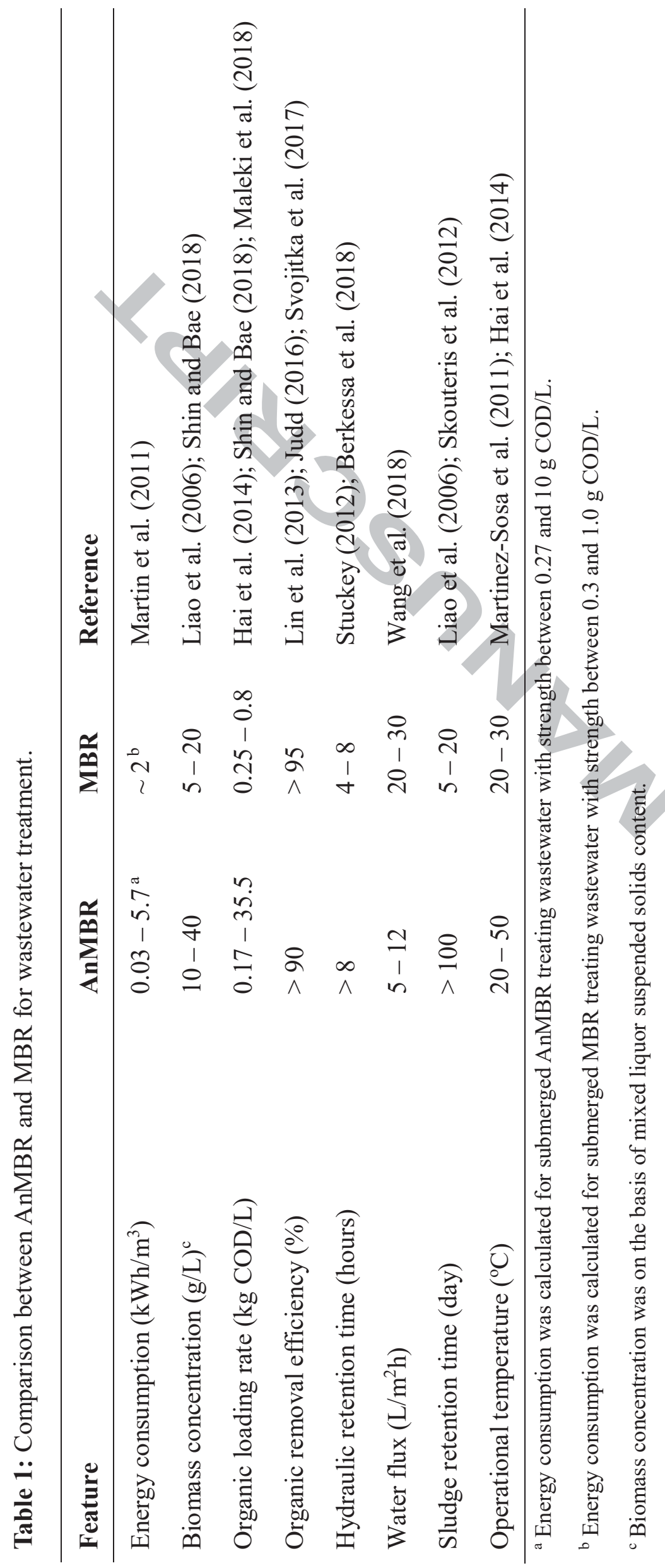




\subsection{Configurations of anaerobic membrane bioreactor}

There are several AnMBR configurations depending on the anaerobic treatment process (Figure 1). Excellent reviews of anaerobic bioreactors for AnMBR are available in the literature (Skouteris et al., 2012; Ozgun et al., 2013; Chen et al., 2016). Common anaerobic bioreactors for AnMBR include up-flow anaerobic sludge blanket (UASB), completely stirred tank reactor (CSTR), and anaerobic fluidized bed bioreactor (AFBR) (Figure 1A-C). Of these reactors, CSTR is the most frequently used configuration for AnMBR due to its ease of construction and operation. UASB can retain biomass mostly in the bottom zone of the bioreactor, thus, the effluent passed through the membrane unit has low suspended solids concentration, which may help alleviating membrane fouling. In UASB, the produced biogas can be captured through a gas/liquid/solid separator. AFBR contains granular media (e.g. activated carbon or sponge) suspended in the reactor by the upward velocity of the treated fluid (Kim et al., 2011).

AnMBR can be operated in either side-stream or submerged mode (Figure 1 D - F). In the side-stream AnMBR, membrane module is integrated outside of the bioreactor. Mixed liquor in the bioreactor is transferred to the membrane unit for clean water extraction. In the submerged AnMBR, membrane unit can be directly immersed into the bioreactor (Figure $1 \mathrm{E}$ ) to extract treated water through the membrane.

The submerged AnMBR can be deployed as a two-stage system by submersing the membrane module in a chamber separated from the working bioreactor (Figure 1F). The two-stage AnMBR configuration facilitates membrane maintenance and cleaning by intensive shear force and chemicals. Retentate from the membrane tank can also be recirculated to the anaerobic reactor for further contaminant biodegradation. As such, the two-stage configuration can be potentially used for full-scale AnMBR applications. Indeed, Shin and Bae (2018) reported that ten out of eleven recent pilot-scale AnMBR studies have adopted the two-stage configuration. As a notable exception, Gouveia et al. (2015b) developed a single-stage AnMBR system, in which a submerged membraned housed at the supper part of the USAB reactor. In their study, two baffles 
were placed between the three-phase (i.e. gas/liquid/solid) separator and the UF membrane to improve solid settleability.

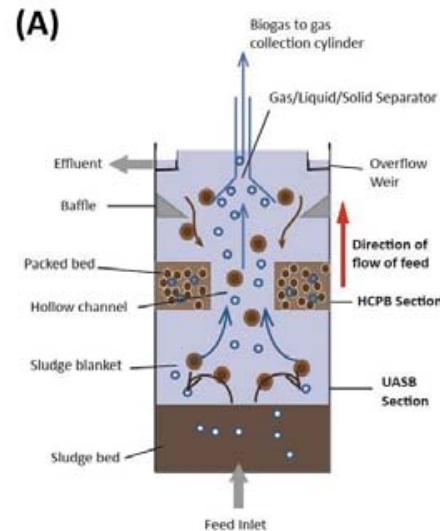

(D)

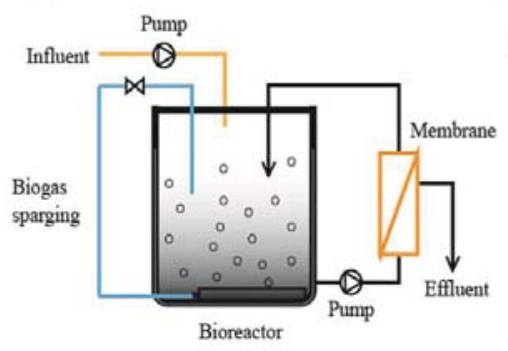

(B)

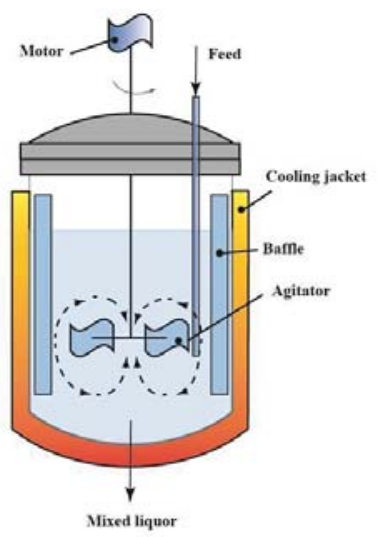

(E)

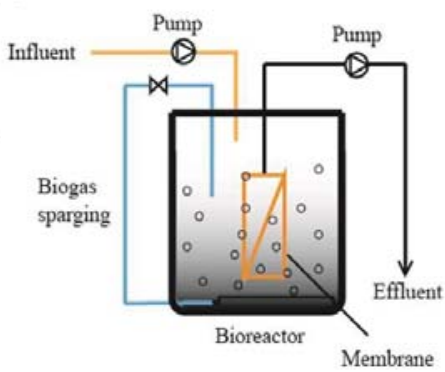

(C)

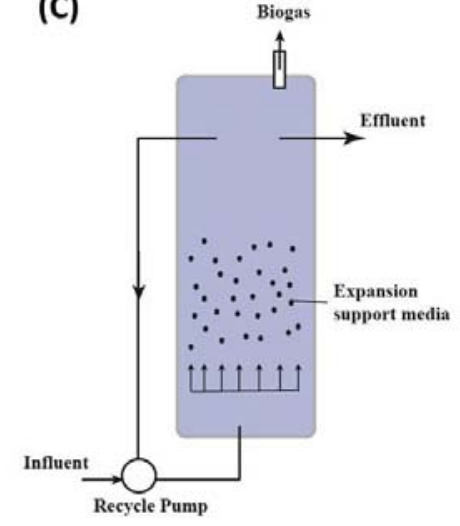

(F)

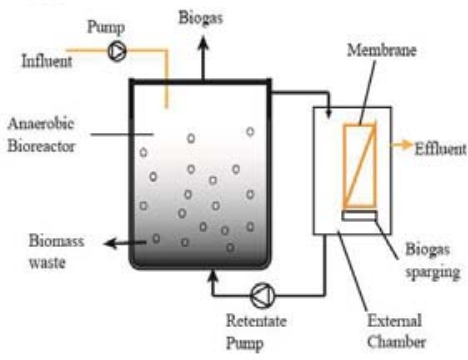

Figure 1: Typical anaerobic bioreactors (A: up-flow anaerobic sludge reactor; B: continuous stirred-tank reactor; C: anaerobic fluidized bed reactor) and their integration with membrane separation process in the (D) side-stream, (E) submerged and $(\mathrm{F})$ external chamber modes.

Recent progress to advance wastewater treatment and reuse has resulted in the emergence of high retention AnMBR systems. These mainly include anaerobic membrane distillation bioreactors (AnMDBR) and anaerobic osmotic membrane bioreactor (AnOMBR). By integrating with the MD or FO process, both AnMDBR and AnOMBR can enhance the removal of contaminants for water reuse applications. AnMDBR is an integration of membrane distillation (MD) and anaerobic treatment. MD is a thermally driven separation processes, in which the thermal gradient between a feed solution and distillate drives the transportation of water vapour through a hydrophobic, microporous membrane. The competitive advantages of anaerobic 
processes can be readily utilized when they are combined with the MD process, because the thermophilic operation for anaerobic treatment can reduce extra heat requirement for MD operation (Kim et al., 2015).

AnOMBR, which combines forward osmosis (FO) with anaerobic treatment, is also attractive for advanced wastewater treatment and reuse. In FO, water transports from a feed solution, across the semi-permeable membrane, to a draw solution with the osmotic pressure difference between these two solutions as the driving force. During AnOMBR operation, a desalination process, such as nanofiltration (NF) and reverse osmosis (RO), can be used to regenerate the draw solution and produce clean water. Compared to conventional MF and UF membranes, FO has higher selectivity, lower membrane fouling propensity and better membrane fouling reversibility (Xie et al., 2015).

\section{Anaerobic membrane bioreactors for water reuse and resource recovery}

\subsection{Organic removal}

The performance of AnMBR for water reuse has been extensively studied in recent years. AnMBR is best suited for the treatment of wastewater with a high organic content. Indeed, there have been a number of pilot demonstration and full-scale AnMBR systems for treating effluents from field crop processing (e.g. sauerkraut, wheat, maize, soybean, and palm oil), dairy processing, and the beverage industry (e.g. winery, brewery, and distillery) (Table 2).

Amongst complex contaminants in wastewater, TrOCs present arguably the most vexing challenge to water reuse (Schwarzenbach et al., 2006). Recent studies have also demonstrated that the removal of TrOCs by AnMBR varied significantly from negligible to more than $90 \%$ (Figure 2). TrOC removal by AnMBR is governed mostly by intrinsic physiochemical properties of the compound. Monsalvo et al. (2014) investigated the removal of 38 TrOCs by AnMBR and reported over 90\% removal of nine compounds; while the others were removed by less than $50 \%$. Wijekoon et al. (2015) have successfully developed a predictive framework to assess the removal of 
TrOCs by AnMBR, which relates the removal of TrOCs to their hydrophobicity and molecular structures. Specifically, hydrophobic TrOCs were effectively removed by more than $70 \%$ as they are prone to adsorb onto sludge for subsequent biodegradation (Figure 2). High removal was also observed for hydrophilic compounds with electron donating groups (e.g. hydroxyl and amine) and nitrogen in the molecular structure. By contrast, hydrophilic compounds with electron withdrawing groups (e.g. chloro and amide) were resistant to AnMBR treatment (Figure 2).

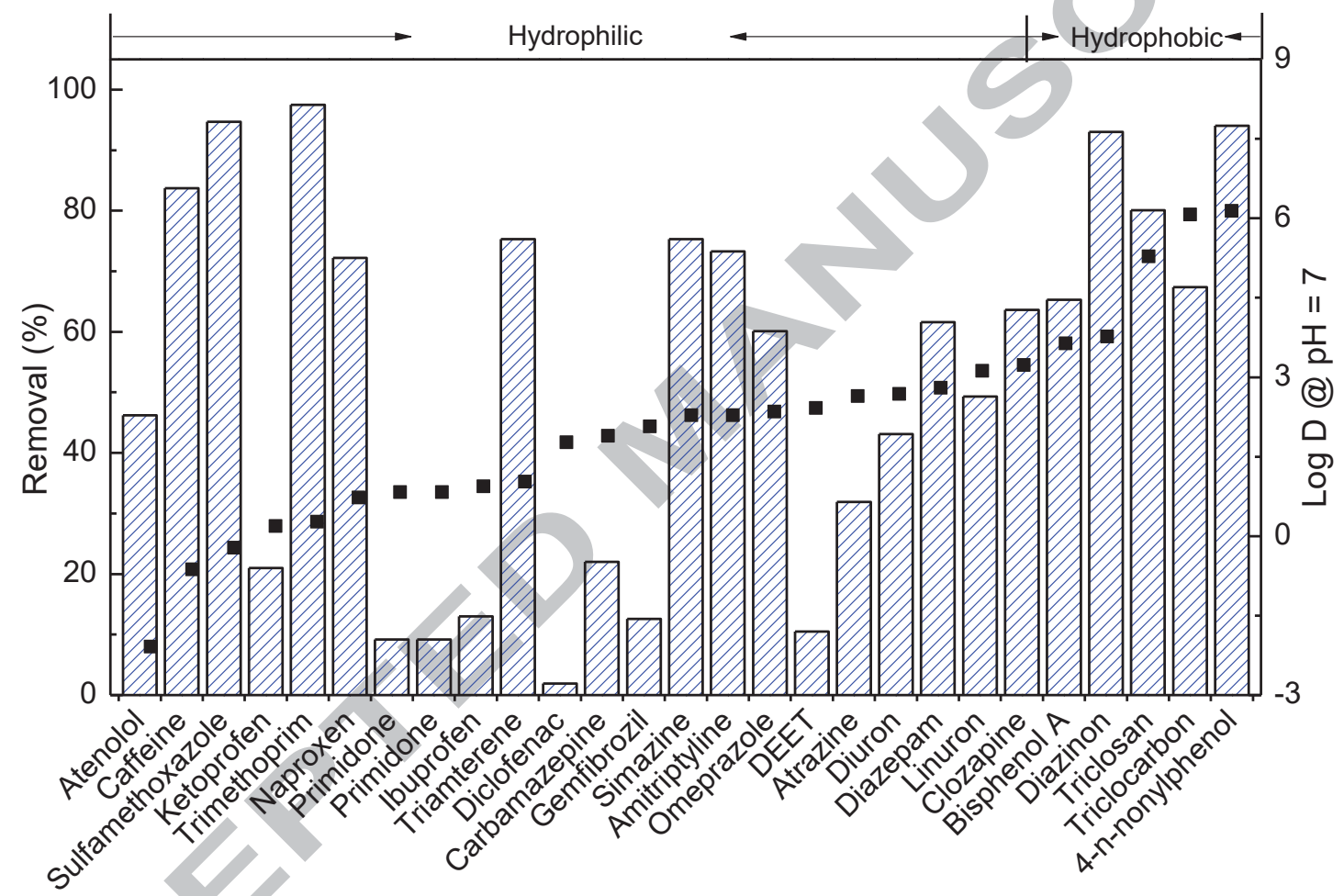

Figure 2: Removal of trace organic contaminants (TrOCs) by AnMBR. Results were extracted from previous studies (Monsalvo et al., 2014; Wijekoon et al., 2015). TrOCs were ordered based on their hydrophobicity, which could be determined by their effective octanol - water partition coefficient (i.e. Log D) at the mixed liquor $\mathrm{pH}$ of 7. 


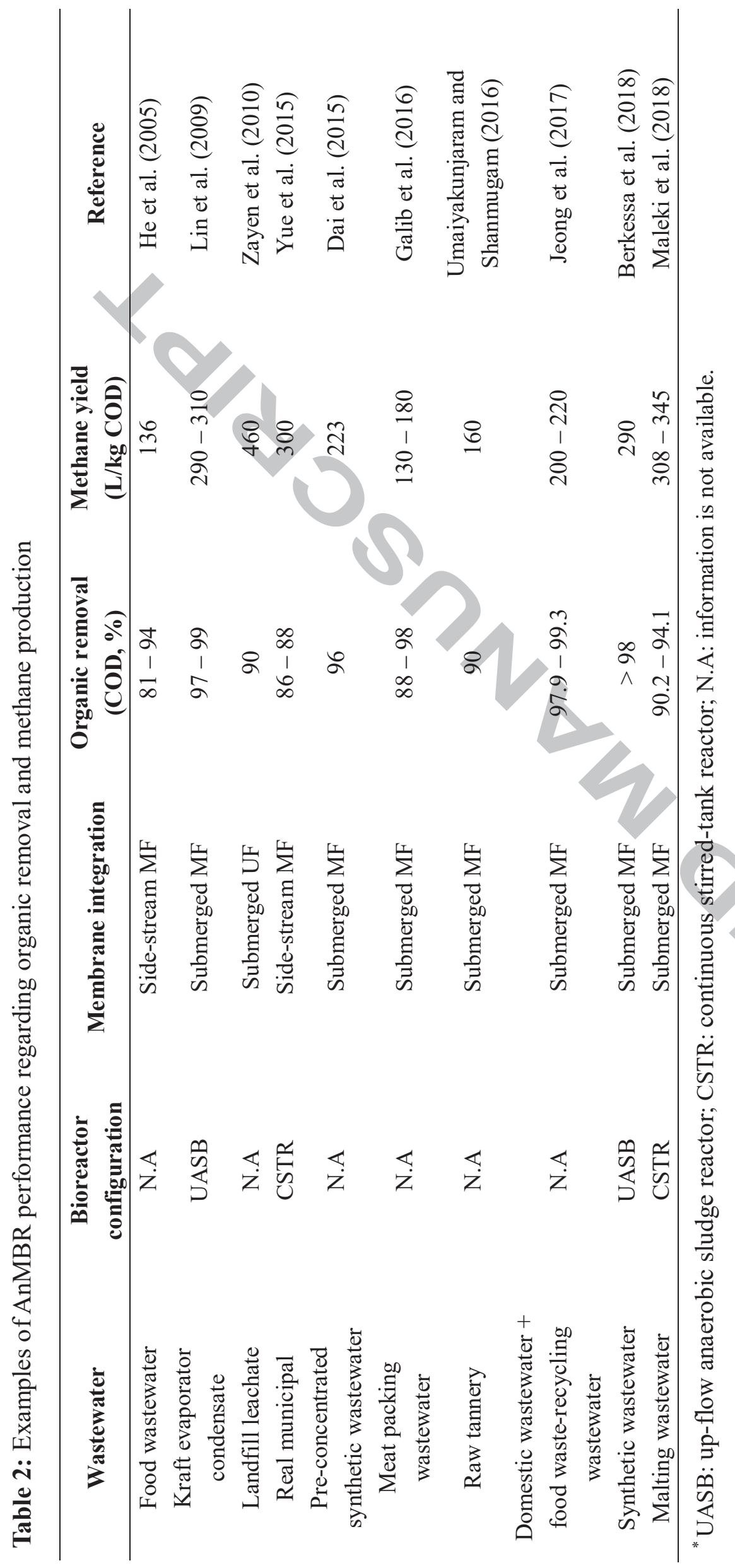




\subsection{Biogas production}

Chemical energy in wastewater in the form of organic carbon can be recovered by AnMBR to produce biogas (Table 2). It has been well established that biogas

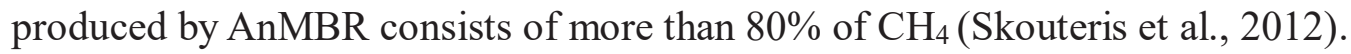
During AnMBR treatment, the $\mathrm{CH}_{4}$ yield increases linearly with the organic loading rate (Yeo et al., 2015). Under an optimized condition, AnMBR can convert up to $98 \%$ of the influent COD into biogas, which is equivalent to seven times of the energy required for system operation (Van Zyl et al., 2008). In practice, actual biogas yield is considerably lower than the theoretical value, due to the high solubility of $\mathrm{CH}_{4}$ in the effluent and process inhibition caused by inhibitory substances.

$\mathrm{CH}_{4}$ loss due to its solubility $(22.7 \mathrm{mg} / \mathrm{L})$ in the effluent is significant during AnMBR treatment, particularly for low strength municipal wastewater (Smith et al., 2012). Liu et al. (2014) reported that dissolved $\mathrm{CH}_{4}$ in permeate was approximately $45 \%$ of total produced $\mathrm{CH}_{4}$ at $30{ }^{\circ} \mathrm{C}$ when $\mathrm{AnMBR}$ was used for treating municipal wastewater with COD of $200 \mathrm{mg} / \mathrm{L}$. Similar results were also reported by Yeo et al. (2015) who observed that $24-58 \%$ of total produced $\mathrm{CH}_{4}$ was dissolved in the permeate during AnMBR treatment and Yue et al. (2015) who demonstrated that AnMBR could remove $86-88 \%$ COD from municipal wastewater (influent COD of approximately $330 \mathrm{mg} / \mathrm{L}$ ), but $67 \%$ of the produced $\mathrm{CH}_{4}$ was dissolved in the mixed liquor and then released via permeate. Galib et al. (2016) reported that the dissolved $\mathrm{CH}_{4}$ concentrations decreased from 54 to $25 \mathrm{mg} / \mathrm{L}$ when the organic loading rate of wastewater increased from 0.4 to $3.2 \mathrm{~kg} \mathrm{COD} / \mathrm{m}^{3} \mathrm{~d}$, due to the enhanced biogas yield at the high organic loading rate.

Dissolved $\mathrm{CH}_{4}$ in the permeate does not only reduce the energy efficiency of AnMBR treatment, but also contribute to global warming as the greenhouse potency of $\mathrm{CH}_{4}$ is 25 times higher than carbon dioxide. Vacuum packed towers, bubble columns and forced drafted aerators can be used to remove $\mathrm{CH}_{4}$ from anaerobically treated effluent (Crone et al., 2016). These processes require a large physical footprint to ensure 
sufficient contact time for gas stripping and prevent operational problems, such as flooding and channelling (Sethunga et al., 2018). Membrane separation process has also been proposed recently to advance dissolved $\mathrm{CH}_{4}$ recovery from anaerobic effluents. Cookney et al. (2016) demonstrated a hollow fibre membrane contactor that could recover more than $98.9 \%$ dissolved $\mathrm{CH}_{4}$ from $\mathrm{AnMBR}$ effluent. However, membrane separation process for the recovery of dissolved $\mathrm{CH}_{4}$ from anaerobic effluents is still in the early stage and its economic viability and process safety have not been fully evaluated. Overall, the dissolution of $\mathrm{CH} 4$ in effluent is still a major limiting factor to the deployment of AnMBR for low strength wastewater (Liu et al., 2014).

\subsection{Nutrient removal and recovery}

During AnMBR treatment, nutrient removal depends largely on microbial assimilation and is limited due to low biomass yields of anaerobic microbes. Dai et al. (2015) reported that AnMBR could only remove $10 \%$ of the total nitrogen. On the other hand, anaerobic treatment liberates nitrogen and phosphorus in the form of ammonium $\left(\mathrm{NH}_{4}{ }^{+}\right)$and phosphate $\left(\mathrm{PO}_{4}{ }^{3}\right)$, respectively, thus facilitating their recovery through subsequent precipitation.

Integrating complementary processes with AnMBR may be necessary to enhance nutrient recovery from AnMBR effluent. These processes include membrane processes (Jacob et al., 2015), ion exchange (Liu et al., 2016), electrodialysis (Xie et al., 2016), and photosynthetic bioreactor (Gonzalez et al., 2017). Deng et al. (2014) demonstrate that natural zeolite as an absorbent can be used to economically remove $\mathrm{NH}_{4}{ }^{+}$from AnMBR effluent. Jacob et al. (2015) reported 90\% removal of COD and ammonium nitrogen from AnMBR effluent by a direct contact MD process. Similar results were reported by Song et al. (2018b) who demonstrated the complementarity between AnMBR and MD for TrOC removal. It is noteworthy that a reduction of $\mathrm{NH}_{4}{ }^{+}$removal was observed in their study due to its transportation through the MD membrane via ammonia evaporation. This issue can be potentially addressed using a FO and MD hybrid system, where the FO membrane can effectively reject $\mathrm{NH}_{4}{ }^{+}$ 
while MD can be used to regenerate the draw solution and produce clean water. Xie et al. (2014) has successfully demonstrated the feasibility of the FO and MD hybrid system for nutrient recovery (as struvite) and clean water production from digested sludge centrate.

Effective nutrient removal can be achieved by high retention AnMBR systems. Chen et al. (2014b) demonstrated that AnOMBR could remove total phosphorus (TP) and $\mathrm{NH}_{4}{ }^{+}$by $100 \%$ and $62 \%$, respectively. The observed complete TP removal was attributed to the high rejection of $\mathrm{PO}_{4}^{3-}$ ions by the $\mathrm{FO}$ membrane given their negative charge and large hydrated radius (Holloway et al., 2007).

\section{Factors underlying key challenges to further develop anaerobic membrane bioreactors}

Despite the high potential of AnMBR for resource recovery from wastewater, there remain some challenges, particularly for treating municipal sewage. They include the dilute nature and temperature difference of municipal wastewater, salinity build-up when diluted wastewater is preconcentrated, membrane fouling and stability, and inhibitory substances (e.g. free ammonia and sulphide) (Figure 3). Thus, future studies are required for the development of effective strategies to address these challenges for further development of AnMBR. 


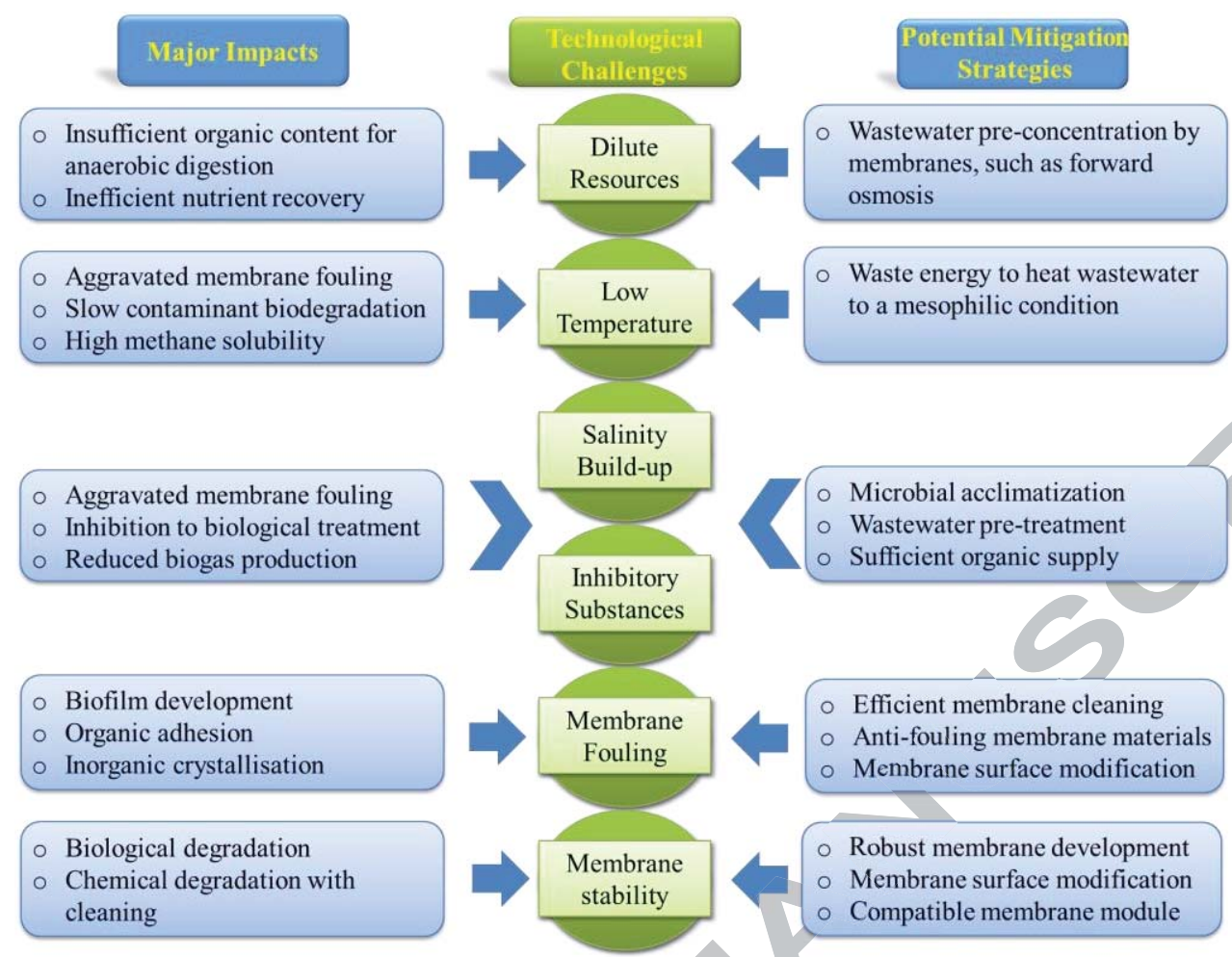

Figure 3: Key challenges and their potential strategies to the development of AnMBR for wastewater treatment and resource recovery.

\subsection{Dilute nature of wastewater}

Municipal wastewater has low concentrations of organic substances (for energy recovery) and even lower concentration of nitrogen and phosphorus (for nutrient recovery). A moderate wastewater strength (> $1000 \mathrm{mg} \mathrm{COD} / \mathrm{L})$ is necessary to maintain effective activity of anaerobic digester for adequate biogas yield and removal of organic pollutants from wastewater (Verstraete et al., 2009). Similarly, ammonium and phosphate concentrations should be higher than $5 \mathrm{~g} \mathrm{NH}_{4}-\mathrm{N} / \mathrm{L}$ and 50 $\mathrm{mg} / \mathrm{L}$, respectively, for economically efficient recovery by conventional processes, such as ion exchange and chemical precipitation. However, municipal wastewater typically contains ammonium and phosphate less than $0.1 \mathrm{~g} \mathrm{NH}_{4}-\mathrm{N} / \mathrm{L}$ (Mulder et al., 2013) and $10 \mathrm{mg} / \mathrm{L}$ (Yuan et al., 2012). Thus, the pre-concentration of municipal wastewater is required prior to AnMBR treatment for the waste-to-resource strategy.

Membrane separation can be used to pre-concentrate wastewater to produce high quality water and simultaneously enrich non-water components for subsequent 
recovery. Currently used membrane processes include MF, UF and RO. As an example, Dai et al. (2015) have successfully used an UF - RO hybrid system to pre-concentrate municipal wastewater for elevating COD and nitrogen concentrations to the levels suitable for AnMBR treatment.

FO is a promising membrane process for wastewater pre-concentration due to its high selectivity, low fouling propensity, and high fouling reversibility (Xie et al., 2013; Ansari et al., 2016). Ansari et al. (2016) demonstrated that FO could concentrate municipal wastewater by more than eight times to a COD range $(>1000 \mathrm{mg} / \mathrm{L})$ suitable for biogas production in anaerobic treatment. Higher concentration factors could be achieved when municipal wastewater was further diluted during rainy seasons (Ansari et al., 2016). FO can be integrated with a desalination process (e.g. $\mathrm{RO}$ and $\mathrm{MD}$ ) for draw solution regeneration and clean water production (Xie et al., 2013). When the recovery of the draw solution, such as seawater, is not needed, FO can also be operated in the energy efficient osmotic dilution mode (Ansari et al., 2016).

Pre-concentration of wastewater may entail several issues to AnMBR. In addition to organic matter, pre-concentrating wastewater can enrich inhibitory substances, such as inorganic salts, ammonia, and sulphate. Salt accumulation in wastewater is significant when using $\mathrm{FO}$ as the pre-concentration process due to its reverse salt flux. Inhibitions of these substances to AnMBR are discussed in the following sections. Moreover, phosphorus may precipitate in the anaerobic reactor due to the enriched content of phosphorus, calcium, and magnesium in pre-concentrated wastewater (Chen et al., 2014a), thereby resulting in significant membrane scaling in AnMBR and complications for subsequent phosphorus recovery as the availability of phosphorus in liquid phase is reduced.

\subsection{Temperature}

AnMBR can be operated under either thermophilic $\left(50-60{ }^{\circ} \mathrm{C}\right)$ or mesophilic $(30-$ $40{ }^{\circ} \mathrm{C}$ ) conditions (Martinez-Sosa et al., 2011; Gouveia et al., 2015a). Psychrophilic 
condition $\left(<20{ }^{\circ} \mathrm{C}\right)$ is generally not suitable for municipal wastewater treatment. Thus, anaerobic treatment of municipal wastewater is still a challenge for cold regions, where significant energy is required to heat wastewater to a mesophilic condition. AnMBR operation at low temperature can result in several negative issues, including aggravated membrane fouling, slow contaminant biodegradation, and high $\mathrm{CH}_{4}$ solubility in the effluent. Hydrolysis of particulate matter into dissolved molecules is limited at low temperature, leading to the accumulation of suspended solids in the reactor and a decrease in methanogenic activity. Martinez-Sosa et al. (2011) observed an increase in the total suspended solids content and soluble COD in the bioreactor when the temperature of AnMBR was reduced from 35 to $20^{\circ} \mathrm{C}$, resulting in severe membrane fouling and decreased $\mathrm{CH}_{4}$ production. The decreased $\mathrm{CH}_{4}$ production could also be attributed to its increased solubility in the effluent when the temperature decreased to $20{ }^{\circ} \mathrm{C}$. In addition, the mixed liquor viscosity also increased as the temperature decreased, thus requiring more energy for mixing and pumping.

\subsection{Salinity build-up}

Saline wastewater is a challenge to biological treatment. Indeed, AnMBR performance in terms of biogas production and organic removal decreases when treating highly saline feed, such as wastewater from seafood processing and cheese production (Dereli et al., 2012). High salinity could result in enzyme inhibition, cell activity decline, and plasmolysis to anaerobic microbes, thereby negatively affecting the anaerobic digestion process (Chen et al., 2008). For instance, Ng et al. (2014) reported that the $\mathrm{CH}_{4}$ yield of AnMBR was reduced to less than $160 \mathrm{~L} / \mathrm{kg} \mathrm{COD}_{\text {removed }}$ when treating pharmaceutical wastewater due to the disrupted ordinary metabolic functions and degradation kinetics under saline concentrations. Song et al. (2016) also reported the adverse effects of increase salinity (up to $15 \mathrm{~g} / \mathrm{L} \mathrm{NaCl}$ ) on COD removal and biogas production of AnMBR.

Microbial acclimatization could lead to the succession of halotolerant and even halophilic bacteria to recover AnMBR performance (Dereli et al., 2012). Jeison et al. 
(2008) revealed that long-term adaption resulted in better salt tolerance, with the observed 50\% activity inhibitory concentration (IC50) value for acetotrophic methanogenesis at approximately $25 \mathrm{~g} / \mathrm{L} \mathrm{NaCl}$. Munoz Sierra et al. (2018) also reported the robustness of AnMBR to short-term, step-wise increase of salinity up to $20 \mathrm{~g} / \mathrm{L} \mathrm{NaCl}$ with significant variation in the microbial community. It is noteworthy that salinity increase exacerbated membrane fouling by reducing sludge particle size in their study.

\subsection{Inhibitory substances}

AnMBR is susceptible to the accumulation of inhibitory substances, such free ammonia and sulphate, in wastewater. Ammonia is generated by the biodegradation of nitrogenous compounds, mostly in the form of protein in wastewater, during anaerobic digestion (Chen et al., 2008). Ammonia toxicity ( $>3500 \mathrm{mg} / \mathrm{L})$ to anaerobic digester can be attributed to direct inhibition to the activity of cytosolic enzymes as well as an increase in the intracellular $\mathrm{pH}$ and/or the concentration of other cations, such as potassium (Kanai et al., 2010). The observed inhibition was due to free ammonia in solution rather than the ammonium ions, whose equilibrium concentrations are dependent on $\mathrm{pH}$ and temperature (Chen et al., 2008). Indeed, free ammonia is more toxic than ionised ammonia, because it can penetrate through the cell membrane and thus result in the disruption of cellular homeostasis, potassium deficiency and/or proton imbalance. A higher temperature and $\mathrm{pH}$ value can exacerbate the inhibition by releasing more free ammonia (Meabe et al., 2013).

High sulphate concentration can also inhibit AnMBR performance. Such inhibition can be attributed to the competition between sulphate reducing bacteria (approximately $2 \mathrm{~g} \mathrm{COD} / \mathrm{g} \mathrm{SO}_{4}-\mathrm{S}_{\text {removed) }}$ and methanogenic microbes for available carbon (Chen et al., 2016). Moreover, sulphate can induce the precipitation of non-alkaline metals in anaerobic reactors, reducing their availability as micro-nutrients for methane producing microbes (Stefanie et al., 1994; Siles et al., 2010). In addition, sulphate reduction produces hydrogen sulphate $\left(\mathrm{H}_{2} \mathrm{~S}\right)$, which is a corrosive, malodourous, and toxic gas (Muyzer \& Stams, 2008; Sarti \& Zaiat, 2011; 
Park et al., 2014). $\mathrm{H}_{2} \mathrm{~S}$ can readily penetrate through microbial cell membrane and denature native proteins inside the cytoplasm producing sulphide and disulphide cross-links between polypeptide chains (Siles et al., 2010).

Sufficient organic supply can mitigate the inhibition of free ammonia and sulphate to AnMBR. Meabe et al. (2013) reported that longer SRT in AnMBR could allow for sufficient acclimatization of biomass to resist ammonia inhibition. Thus, no critical ammonia inhibition was observed for both mesophilic and thermophilic AnMBR in their study. Tian et al. (2018) recently developed a stepwise acclimation strategy to allow anaerobic communities to adapt to $10 \mathrm{~g} \mathrm{NH}_{4}{ }^{+}-\mathrm{N} / \mathrm{L}$ in mesophilic CSTR. The negative impact of sulphate is also insignificant provided that the ratio of COD and $\mathrm{SO}_{4}{ }^{2-}$ is above 10 (Rinzema \& Lettinga, 1988). In some cases, sulphate addition is beneficial to methane production by boosting the degradation of propionic acid ( $\mathrm{Li}$ et al., 2015). Song et al. (2018a) investigated the effect of sulphate increase on the performance of AnMBR and reported that basic biological performance of AnMBR was not affected by the increased sulphate concentration when the influent $\mathrm{COD} / \mathrm{SO}_{4}{ }^{2-}$ ratio was maintained higher than 10 . Nevertheless, $\mathrm{H}_{2} \mathrm{~S}$ content in the produced biogas increased significantly and membrane fouling was exacerbated with sulphate addition (Song et al., 2018a). Thus, some physicochemical techniques (e.g. striping, $\mathrm{pH}$ adjustment, coagulation, and precipitation) should be applied to reduce sulphate load to AnMBR to secure biogas quality and sustain membrane performance (Yuan \& Zhu, 2016).

\subsection{Membrane fouling}

Membrane fouling is a persistent challenge to advance AnMBR given membrane material costs and energy demands for fouling control and cleaning. Fouling results from the accumulation of inorganic and organic foulants internally in membrane pores and externally on the membrane surface. Membrane fouling can reduce flux, increase transmembrane pressure, and consequently necessitate chemical cleaning or membrane replacement. The primary foulants of interest in AnMBR include suspended biomass, colloidal solids, SMP, EPS, attached cells, and inorganic 
precipitates, such as struvite (Smith et al., 2012). Jun et al. (2017) reported that long-term operation (around 700 days) of AnMBR encountered frequent, sudden irreversible fouling due to biologically induced mineral scaling, thus, intense chemical cleaning was required to recover membrane permeability.

Membrane fouling during AnMBR treatment is governed mainly by membrane properties and operational conditions (e.g. water flux, temperature, HRT, and SRT), hydrodynamics, and sludge characteristics. For instances, Lin et al. (2009) shown that the filtration resistance in thermophilic AnMBR was about 5-10 times higher than that of the mesophilic system when operated under similar hydrodynamic conditions. This observation was due to more SMP, biopolymer clusters, and fine flocs $(<15 \mathrm{~mm})$ under the thermophilic condition. Huang et al. (2011) reported that a decrease in HRT enhanced biomass growth and SMP accumulation, while longer SRT reduced the flocculation of particulates and particle size, thereby aggravating membrane fouling. Thus, membrane fouling in AnMBR can be potentially mitigated to some extent by optimising the operational conditions.

Several techniques have been developed to control and clean membrane fouling during AnMBR operation. In the side-stream AnMBR, high cross-flow velocity can reduce foulant build-up on the membrane surface; while fouling control is typically accomplished through biogas sparging for the submerged configuration. Stuckey (2012) reported that the addition of powdered or granular activated carbon could effectively reduce membrane fouling in AnMBR, however, their long-term effects membrane integrity have yet been investigated. In addition, wastewater pre-treatment, membrane relaxation, and sub-critical flux operation can also control membrane fouling for AnMBR.

Despite effective strategies to control fouling, membrane cleaning is still necessary. Membrane cleaning includes physical, chemical, and biological schemes. Physical membrane cleaning can be achieved by backwashing, surface flushing, and ultrasonication (Lin et al., 2013). Chemical cleaning is necessary to further remove fouling layers using suitable agents, such as sodium hypochlorite, hydrochloric acid, 
nitric acid, citric acid, sodium hydroxide, and EDTA for target foulants.

Chemically-assisted backwashing has also been developed to enhance membrane cleaning for AnMBR. Nevertheless, chemicals that can diffuse back to the bioreactor may inhibit the microbial activity and then biological performance of AnMBR. Mei et al. (2017) reported that utilising $12 \mathrm{mmol} / \mathrm{L} \mathrm{NaOH}$ to assist in-situ membrane backflush did not adversely affect AnMBR treatment performance given the alkali consumption by anaerobic biomass and buffering capacity of the mixed liquid.

\subsection{Membrane stability}

Chemically and biologically stable polymeric materials are commonly used to fabricate robust membranes for MBR applications. These polymeric materials mainly include polytetrafluoroethylene, polyvinylidenefluoride, and polypropylene (Alkhudhiri et al., 2012). Thus, membrane degradation is not a concern for conventional MBR using the existing low retention UF or MF membranes. By contrast, membrane integrity is a major issue to FO when integrating with biological processes.

Currently commercial FO membranes are made of either cellulose or polyamide.

Chen et al. (2014b) observed a sudden increase in the electrical conductivity of the mixed liquor (over 20 times) after an AnOMBR using a CTA FO membrane was operated for 76 days. They also attributed this observation to membrane biodegradation or hydrolysis in the bioreactor.

Both cellulose and polyamide membranes are susceptible to biological and chemical degradation. Cellulose membrane itself can become a substrate for microbial growth. Polyamide TFC membranes appears to be more persistent to biodegradation and hydrolysis than cellulose based membranes (Choi et al., 2005). Nevertheless, some microbial species, such as strains of Pseudomonas sp., in activated sludge may biodegrade polyamides by producing extracellular enzymes to hydrolyse amide bonds (Yamano et al., 2008). On the other hand, polyamide membrane is more susceptible to chemical attack by oxidising agents such as chlorine (Simon et al., 2009). 
Membrane stability determines the product water quality and the sustainability of AnMBR. Thus, it is essential to develop techniques to prevent biological and chemical degradation of membranes in AnOMBR operation. New and robust membrane materials are required to facilitate the integration of FO with AnMBR for resource recovery. Module modification to allow for in-situ membrane cleaning can also potentially control membrane biodegradation (Choi et al., 2002).

\section{Future perspectives}

AnMBR has a proven capability and can offer a unique opportunity to achieve simultaneous wastewater treatment and resource recovery. However, the adoption and commercialisation of AnMBR at industrial scale is still pending due to the challenges discussed above. Thus, future research should be dedicated to address these issues for the further development of AnMBR (Figure 3).

FO is a promising approach to produce clean water and pre-concentrate wastewater to the level suitable for AnMBR treatment (Ansari et al., 2017). Yet, FO technology is still in the early stage of development and requires research efforts for the realisation of full-scale implementation. Moreover, wastewater pre-concentration results in the enrichment of some inhibitory substances (salts, free ammonia, and sulphate) to AnMBR. Thus, techniques for the removal of these inhibitory substances should be developed to secure the performance of AnMBR for treating concentrated wastewater. Membrane fouling in AnMBR is often more severe than aerobic MBR due to the absence of aeration and lower sludge filterability (Skouteris et al., 2012). Thus, advanced techniques to control membrane fouling during AnMBR operation should be developed in addition to the optimisation of operational parameters. Using a low fouling alternative, such as FO, is a potential strategy, which can also enhance contaminant removal in comparison to MF and UF membranes that are commonly used for AnMBR.

Compared to membrane fouling, little is known about the stability of membranes during AnMBR operation. In AnMBR, membranes are exposed to the biologically 
active conditions with biomass concentration typically higher than $10 \mathrm{~g} / \mathrm{L}$. Moreover, given the severity of membrane fouling in AnMBR operation, frequent membrane cleaning with harsh chemicals may be necessary to maintain water production. Thus, it is important to understand membrane degradation in AnMBR operation and develop mitigation strategies to prolong membrane lifespan.

Several techniques have been proposed to further purify AnMBR effluent for clean water production and/or nutrient recovery. They include membrane filtration, ion exchange, electrodialysis, biological processes (e.g. photosynthetic bioreactor), advanced oxidation processes, and electrocoagulation. Nevertheless, further work is needed to evaluate the techno-economic feasibility of these processes in integration with AnMBR to determine an appropriate framework that can facilitate practical application of AnMBR for wastewater treatment and resource recovery. Moreover, the agronomic availability of recovered nutrients should be assessed to emphasize AnMBR potential for resource recovery from wastewater.

Recovering dissolved $\mathrm{CH}_{4}$ from effluent is also strategically important to broaden AnMBR applications towards low organic content wastewater. Recent studies have demonstrated that the promise of membrane-based processes for the recovery of dissolved $\mathrm{CH}_{4}$ from AnMBR effluent (Cookney et al., 2016; Crone et al., 2016; Sethunga et al., 2018), while their economic feasibility has not yet been fully evaluated. Moreover, micro-porous membranes used for gas stripping are threatened by membrane fouling and wetting. As such, continued efforts should be devoted to the development of gas-permeable membranes suitable for $\mathrm{CH}_{4}$ fraction from AnMBR effluent.

\section{Conclusion}

AnMBR has the potential to revolutionise current wastewater treatment facilities for simultaneous recovery of clean water, energy, and nutrients. Such revolution can be accelerated by continued efforts to concentrate municipal wastewater to the level suitable for AnMBR treatment and subsequent resource recovery. Issues associated 
with salinity build-up, membrane stability and fouling, and the occurrence of inhibitory substances (e.g. free ammonia and sulphate) need to be addressed to advance AnMBR for water reuse and resource recovery. Successful recovery of clean water, energy and nutrient also requires the integration between AnMBR and other complementary processes.

\section{Acknowledgement}

Xiaoye Song would like to thank the Chinese Scholarship Council and the University of Wollongong for $\mathrm{PhD}$ scholarship support.

\section{Reference}

[1] Alkhudhiri, A., Darwish, N., Hilal, N. 2012. Membrane distillation: A comprehensive review. Desalination, 287, 2-18.

[2] Ansari, A.J., Hai, F.I., Guo, W., Ngo, H.H., Price, W.E., Nghiem, L.D. 2016. Factors governing the pre-concentration of wastewater using forward osmosis for subsequent resource recovery. Sci. Total Environ., 566-567, 559-566.

[3] Ansari, A.J., Hai, F.I., Price, W.E., Drewes, J.E., Nghiem, L.D. 2017. Forward osmosis as a platform for resource recovery from municipal wastewater - A critical assessment of the literature. J. Membr. Sci., 529, 195-206.

[4] Berkessa, Y.W., Yan, B., Li, T., Tan, M., She, Z., Jegatheesan, V., Jiang, H., Zhang, Y. 2018. Novel anaerobic membrane bioreactor (AnMBR) design for wastewater treatment at long HRT and high solid concentration. Bioresour. Technol., 250, 281-289.

[5] Burn, S., Muster, T., Kaksonen, A., Tjandraatmadja, G. 2014. Resource Recovery from Wastewater: A Research Agenda

[6] Chen, C., Guo, W., Ngo, H.H., Lee, D.-J., Tung, K.-L., Jin, P., Wang, J., Wu, Y. 2016. Challenges in biogas production from anaerobic membrane bioreactors. Renew. Energy, 98, 120-134.

[7] Chen, J.L., Ortiz, R., Steele, T.W., Stuckey, D.C. 2014a. Toxicants inhibiting anaerobic digestion: a review. Biotechnol Adv., 32(8), 1523-1534. 
[8] Chen, L., Gu, Y., Cao, C., Zhang, J., Ng, J.W., Tang, C. 2014b. Performance of a submerged anaerobic membrane bioreactor with forward osmosis membrane for low-strength wastewater treatment. Water Res., 50, 114-123.

[9] Chen, Y., Cheng, J.J., Creamer, K.S. 2008. Inhibition of anaerobic digestion process: a review. Bioresour. Technol., 99(10), 4044-4064.

[10]Choi, J.H., Dockko, S., Fukushi, K., Yamamoto, K. 2002. A novel application of a submerged nanofiltration membrane bioreactor (NF MBR) for wastewater treatment. Desalination, 146(1), 413-420.

[11]Choi, J.H., Fukushi, K., Yamamoto, K. 2005. Comparison of treatment efficiency of submerged nanofiltration membrane bioreactors using cellulose triacetate and polyamide membrane.

[12]Cookney, J., McLeod, A., Mathioudakis, V., Ncube, P., Soares, A., Jefferson, B., McAdam, E.J. 2016. Dissolved methane recovery from anaerobic effluents using hollow fibre membrane contactors. Journal of Membrane Science, 502, 141-150.

[13]Crone, B.C., Garland, J.L., Sorial, G.A., Vane, L.M. 2016. Significance of dissolved methane in effluents of anaerobically treated low strength wastewater and potential for recovery as an energy product: A review. Water Res, 104, $520-531$

[14]Dai, W., Xu, X., Liu, B., Yang, F. 2015. Toward energy-neutral wastewater treatment: A membrane combined process of anaerobic digestion and nitritation-anammox for biogas recovery and nitrogen removal. Chem. Eng. J., $279,725-734$.

[15]Deng, Q., Dhar, B.R., Elbeshbishy, E., Lee, H.S. 2014. Ammonium nitrogen removal from the permeates of anaerobic membrane bioreactors: economic regeneration of exhausted zeolite. Environ. Technol., 35(13-16), 2008-2017.

[16]Dereli, R.K., Ersahin, M.E., Ozgun, H., Ozturk, I., Jeison, D., van der Zee, F., van Lier, J.B. 2012. Potentials of anaerobic membrane bioreactors to overcome 
treatment limitations induced by industrial wastewaters. Bioresour. Technol., $122,160-170$.

[17]Doyle, J.D., Oldring, K., Churchley, J., Parsons, S.A. 2002. Struvite formation and the fouling propensity of different materials. Water Res., 36, 3971-3978.

[18]Galib, M., Elbeshbishy, E., Reid, R., Hussain, A., Lee, H.S. 2016.

Energy-positive food wastewater treatment using an anaerobic membrane bioreactor (AnMBR). J. Environ. Manage., 182, 477-485.

[19]Gao, J., Liu, L., Liu, X., Lu, J., Zhou, H., Huang, S., Wang, Z., Spear, P.A. 2008. Occurrence and distribution of organochlorine pesticides - lindane, p,p'-DDT, and heptachlor epoxide - in surface water of China. Environ. Int., 34(8), 1097-103.

[20]Gonzalez, E., Diaz, O., Ruigomez, I., de Vera, C.R., Rodriguez-Gomez, L.E., Rodriguez-Sevilla, J., Vera, L. 2017. Photosynthetic bacteria-based membrane bioreactor as post-treatment of an anaerobic membrane bioreactor effluent. Bioresour Technol, 239, 528-532.

[21] Gouveia, J., Plaza, F., Garralon, G., Fdz-Polanco, F., Pena, M. 2015a. Long-term operation of a pilot scale anaerobic membrane bioreactor (AnMBR) for the treatment of municipal wastewater under psychrophilic conditions. Bioresour. Technol., 185, 225-233.

[22] Gouveia, J., Plaza, F., Garralon, G., Fdz-Polanco, F., Pena, M. 2015b. A novel configuration for an anaerobic submerged membrane bioreactor (AnSMBR). Long-term treatment of municipal wastewater under psychrophilic conditions. Bioresour. Technol., 198, 510-519.

[23]Hai, F.I., Yamamoto, K., Lee, C.H. 2014. Membrane Biological Reactors: Theory, Modeling, Design, Management and Applications to Wastewater Reuse. IWA Publishing, London.

[24]He, Y., Xu, P., Li, C., Zhang, B. 2005. High-concentration food wastewater treatment by an anaerobic membrane bioreactor. Water Res., 39(17), 4110-8. 
[25]Holloway, R.W., Childress, A.E., Dennett, K.E., Cath, T.Y. 2007. Forward osmosis for concentration of anaerobic digester centrate. Water Res., 41(17), 4005-4014.

[26]Huang, Z., Ong, S.L., Ng, H.Y. 2011. Submerged anaerobic membrane bioreactor for low-strength wastewater treatment: effect of HRT and SRT on treatment performance and membrane fouling. Water Res., 45(2), 705-713.

[27]Jacob, P., Phungsai, P., Fukushi, K., Visvanathan, C. 2015. Direct contact membrane distillation for anaerobic effluent treatment. J. Membr. Sci., 475, 330-339.

[28]Jeison, D., Kremer, B., van Lier, J.B. 2008. Application of membrane enhanced biomass retention to the anaerobic treatment of acidified wastewaters under extreme saline conditions. Sep. Purif. Technol., 64(2), 198-205.

[29]Jeong, Y., Hermanowicz, S.W., Park, C. 2017. Treatment of food waste recycling wastewater using anaerobic ceramic membrane bioreactor for biogas production in mainstream treatment process of domestic wastewater. Water Res., $123,86-95$.

[30]Judd, S.J. 2016. The status of industrial and municipal effluent treatment with membrane bioreactor technology. Chem. Eng. J., 305, 37-45.

[31]Jun, D., Kim, Y., Hafeznezami, S., Yoo, K., Hoek, E.M.V., Kim, J. 2017. Biologically induced mineralization in anaerobic membrane bioreactors: Assessment of membrane scaling mechanisms in a long-term pilot study. J. Membr. Sci., 543, 342-350.

[32]Kanai, M., Ferre, V., Wakahara, S., Yamamoto, T., Moro, M. 2010. A novel combination of methane fermentation and MBR - Kubota Submerged Anaerobic Membrane Bioreactor process. Desalination, 250(3), 964-967.

[33]Kim, H.C., Shin, J., Won, S., Lee, J.Y., Maeng, S.K., Song, K.G. 2015. Membrane distillation combined with an anaerobic moving bed biofilm reactor for treating municipal wastewater. Water Res., 71, 97-106. 
[34]Kim, J., Kim, K., Ye, H., Lee, E., Shin, G., Mccarty, P., Bae, J. 2011. Anaerobic fluidized bed membrane bioreactor for wastewater treatment. Environ. Sci. Technol., 45, 576-581.

[35]Koppelaar, R.H.E.M., Weikard, H.P. 2013. Assessing phosphate rock depletion and phosphorus recycling options. Global Environ. Change, 23(6), 1454-1466.

[36]Li, Q., Li, Y.Y., Qiao, W., Wang, X., Takayanagi, K. 2015. Sulfate addition as an effective method to improve methane fermentation performance and propionate degradation in thermophilic anaerobic co-digestion of coffee grounds, milk and waste activated sludge with AnMBR. Bioresour. Technol., 185, 308-315.

[37]Liao, B.Q., Kraemer, J.T., Bagley, D.M. 2006. Anaerobic Membrane Bioreactors: Applications and Research Directions. Environ. Sci. Technol., $36(6), 489-530$.

[38]Lin, H., Peng, W., Zhang, M., Chen, J., Hong, H., Zhang, Y. 2013. A review on anaerobic membrane bioreactors: Applications, membrane fouling and future perspectives. Desalination, 314, 169-188.

[39]Lin, H.J., Xie, K., Mahendran, B., Bagley, D.M., Leung, K.T., Liss, S.N., Liao, B.Q. 2009. Sludge properties and their effects on membrane fouling in submerged anaerobic membrane bioreactors (SAnMBRs). Water Res., 43(15), 3827-3837.

[40]Liu, C., Wang, Q., Huang, F., Zhang, J. 2016. Removal of phosphorus from anaerobic membrane bioreactor effluent by ion exchange resin. Sep. Sci. Technol., 51(17), 2833-2843.

[41]Liu, Z.H., Yin, H., Dang, Z., Liu, Y. 2014. Dissolved methane: a hurdle for anaerobic treatment of municipal wastewater. Environ. Sci. Technol., 48(2), 889-890.

[42]Luo, Y., Guo, W., Ngo, H.H., Nghiem, L.D., Hai, F.I., Zhang, J., Liang, S., Wang, X.C. 2014. A review on the occurrence of micropollutants in the aquatic 
environment and their fate and removal during wastewater treatment. Sci. Total Environ., 473-474, 619-641.

[43]Maleki, E., Catalan, L.J.J., Liao, B. 2018. Effect of organic loading rate on the performance of a submerged anaerobic membrane bioreactor (SAnMBR) for malting wastewater treatment and biogas production. Journal of Chem. Technol. Biotechnol., 93(6), 1636-1647.

[44]Martin, I., Pidou, M., Soares, A., Judd, S., Jefferson, B. 2011. Modelling the energy demands of aerobic and anaerobic membrane bioreactors for wastewater treatment. Environ. Technol., 32(9-10), 921-932.

[45]Martinez-Sosa, D., Helmreich, B., Netter, T., Paris, S., Bischof, F., Horn, H. 2011. Anaerobic submerged membrane bioreactor (AnSMBR) for municipal wastewater treatment under mesophilic and psychrophilic temperature conditions. Bioresour. Technol., 102(22), 10377-85.

[46]McCarty, P.L., Bae, J., Kim, J. 2011. Domestic wastewater treatment as a net energy producer--can this be achieved? Environ. Sci. Technol., 45(17), $7100-7106$.

[47]Meabe, E., Déléris, S., Soroa, S., Sancho, L. 2013. Performance of anaerobic membrane bioreactor for sewage sludge treatment: Mesophilic and thermophilic processes. J. Membr. Sci., 446, 26-33.

[48]Mei, X., Quek, P.J., Wang, Z., Ng, H.Y. 2017. Alkali-assisted membrane cleaning for fouling control of anaerobic ceramic membrane bioreactor. Bioresour. Technol., 240, 25-32.

[49]Monsalvo, V.M., McDonald, J.A., Khan, S.J., Le-Clech, P. 2014. Removal of trace organics by anaerobic membrane bioreactors. Water Res., 49, 103-112. [50]Munoz Sierra, J.D., Oosterkamp, M.J., Wang, W., Spanjers, H., van Lier, J.B. 2018. Impact of long-term salinity exposure in anaerobic membrane bioreactors treating phenolic wastewater: Performance robustness and endured microbial community. Water Res., 141, 172-184. 
[51]Muyzer, G., Stams, A.J. 2008. The ecology and biotechnology of sulphate-reducing bacteria. Nat. Rev. Microbiol., 6(6), 441-454.

[52]Ng, K.K., Shi, X., Tang, M.K.Y., Ng, H.Y. 2014. A novel application of anaerobic bio-entrapped membrane reactor for the treatment of chemical synthesis-based pharmaceutical wastewater. Sep. Purif. Technol., 132, 634-643.

[53]Ozgun, H., Dereli, R.K., Ersahin, M.E., Kinaci, C., Spanjers, H., van Lier, J.B. 2013. A review of anaerobic membrane bioreactors for municipal wastewater treatment: Integration options, limitations and expectations. Sep. Purif. Technol., 118, 89-104.

[54]Park, K., Lee, H., Phelan, S., Liyanaarachchi, S., Marleni, N., Navaratna, D., Jegatheesan, V., Shu, L. 2014. Mitigation strategies of hydrogen sulphide emission in sewer networks - A review. Int. Biodeterior. Biodegrad., 95, 251-261.

[55]Rinzema, A., Lettinga, G. 1988. Anaerobic treatment of sulfate containing wastewater. in: Biotreatment systems (Ed.) D.L. Wise, pp. 65-110.

[56] Sarti, A., Zaiat, M. 2011. Anaerobic treatment of sulfate-rich wastewater in an anaerobic sequential batch reactor (AnSBR) using butanol as the carbon source. J. Environ. Manage., 92(6), 1537-1541.

[57] Schwarzenbach, R.P., Escher, B.I., Fenner, K., Hofstetter, T.B., Johnson, C.A., von Gunten, U., Wehrli, B. 2006. The Challenge of Micropollutants in Aquatic Systems. Science, 313(5790), 1072-1077.

[58] Sethunga, G.S.M.D.P., Rongwong, W., Wang, R., Bae, T.-H. 2018. Optimization of hydrophobic modification parameters of microporous polyvinylidene fluoride hollow-fiber membrane for biogas recovery from anaerobic membrane bioreactor effluent. J. Membr. Sci., 548, 510-518.

[59] Shannon, M.A., Bohn, P.W., Elimelech, M., Georgiadis, J.G., Marinas, B.J., Mayes, A.M. 2008. Science and technology for water purification in the coming decades. Nature, 452(7185), 301-310. 
[60] Shin, C., Bae, J. 2018. Current status of the pilot-scale anaerobic membrane bioreactor treatments of domestic wastewaters: A critical review. Bioresour. Technol., 247, 1038-1046.

[61]Siles, J.A., Brekelmans, J., Martin, M.A., Chica, A.F., Martin, A. 2010. Impact of ammonia and sulphate concentration on thermophilic anaerobic digestion. Bioresour. Technol., 101(23), 9040-9048.

[62]Simon, A., Nghiem, L.D., Le Clech, P., Khan, S.J., Drewes, J.E. 2009. Effects of membrane degradation on the removal of pharmaceutically active compounds (PhACs) by NF/RO filtration processes. J. Membr. Sci., 340(1), 16-25.

[63] Skouteris, G., Hermosilla, D., López, P., Negro, C., Blanco, Á. 2012. Anaerobic membrane bioreactors for wastewater treatment: A review. Chem. Eng. J., 198-199, 138-148.

[64] Smith, A.L., Stadler, L.B., Love, N.G., Skerlos, S.J., Raskin, L. 2012. Perspectives on anaerobic membrane bioreactor treatment of domestic wastewater: a critical review. Bioresour. Technol., 122, 149-159.

[65]Song, X., Luo, W., McDonald, J., Khan, S.J., Hai, F.I., Guo, W., Ngo, H.H., Nghiem, L.D. 2018a. Effects of sulphur on the performance of an anaerobic membrane bioreactor: Biological stability, trace organic contaminant removal, and membrane fouling. Bioresour. Technol., 250, 171-177.

[66]Song, X., Luo, W., McDonald, J., Khan, S.J., Hai, F.I., Price, W.E., Nghiem, L.D. 2018b. An anaerobic membrane bioreactor - membrane distillation hybrid system for energy recovery and water reuse: Removal performance of organic carbon, nutrients, and trace organic contaminants. Sci. Total Environ., 628-629, $358-365$.

[67]Song, X., McDonald, J., Price, W.E., Khan, S.J., Hai, F.I., Ngo, H.H., Guo, W., Nghiem, L.D. 2016. Effects of salinity build-up on the performance of an anaerobic membrane bioreactor regarding basic water quality parameters and removal of trace organic contaminants. Bioresour. Technol., 216, 399-405. 
[68] Stefanie, J.W.H., Elferink, O., Visser, A., Hulshoff Pol, L.W., Stams, A.J.M. 1994. Sulfate reduction in methanogenic bioreactors. FEMS Microbiol. Rev., 15(2), 119-136.

[69] Stuckey, D.C. 2012. Review: Recent developments in anaerobic membrane reactors. Bioresour. Technol., 122, 137-148.

[70]Svojitka, J., Dvorak, L., Studer, M., Straub, J.O., Fromelt, H., Wintgens, T. 2017. Performance of an anaerobic membrane bioreactor for pharmaceutical wastewater treatment. Bioresour Technol, 229, 180-189.

[71]Tian, H., Fotidis, I.A., Mancini, E., Treu, L., Mahdy, A., Ballesteros, M., Gonzalez-Fernandez, C., Angelidaki, I. 2018. Acclimation to extremely high ammonia levels in continuous biomethanation process and the associated microbial community dynamics. Bioresour. Technol., 247, 616-623.

[72]Umaiyakunjaram, R., Shanmugam, P. 2016. Study on submerged anaerobic membrane bioreactor (SAMBR) treating high suspended solids raw tannery wastewater for biogas production. Bioresour. Technol., 216, 785-792.

[73] Van Zyl, P.J., Wentzel, M.C., Ekama, G.A., Riedel, K.J. 2008. Design and start-up of a high rate anaerobic membrane bioreactor for the treatment of a low $\mathrm{pH}$, high strength, dissolved organic waste water. Water Sci. Technol., 57(2), $291-295$

[74] Verstraete, W., Van de Caveye, P., Diamantis, V. 2009. Maximum use of resources present in domestic "used water". Bioresour. Technol., 100(23), $5537-5545$.

[75]Wang, K.M., Jefferson, B., Soares, A., McAdam, E.J. 2018. Sustaining membrane permeability during unsteady-state operation of anaerobic membrane bioreactors for municipal wastewater treatment following peak-flow. Journal of Membrane Science, 564, 289-297.

[76]Wijekoon, K.C., McDonald, J.A., Khan, S.J., Hai, F.I., Price, W.E., Nghiem, L.D. 2015. Development of a predictive framework to assess the removal of 
trace organic chemicals by anaerobic membrane bioreactor. Bioresour. Technol., 189, 391-398.

[77]Xie, M., Lee, J., Nghiem, L.D., Elimelech, M. 2015. Role of pressure in organic fouling in forward osmosis and reverse osmosis. J. Membr. Sci., 493, 748-754.

[78]Xie, M., Nghiem, L.D., Price, W.E., Elimelech, M. 2013. A forward osmosis-membrane distillation hybrid process for direct sewer mining: system performance and limitations. Environ. Sci. Technol., 47(23), 13486-13493.

[79]Xie, M., Nghiem, L.D., Price, W.E., Elimelech, M. 2014. Toward resource recovery from wastewater: Extraction of phosphorus from digested sludge using a hybrid forward osmosis-membrane distillation process. Environ. sci. Technol. Lett., 1(2), 191-195.

[80]Xie, M., Shon, H.K., Gray, S.R., Elimelech, M. 2016. Membrane-based processes for wastewater nutrient recovery: Technology, challenges, and future direction. Water Res., 89, 210-21.

[81] Yamano, N., Nakayama, A., Kawasaki, N., Yamamoto, N., Aiba, S. 2008. Mechanism and characterization of polyamide 4 degradation by Pseudomonas sp. J. Polym. Environ., 16(2), 141-146.

[82]Yeo, H., An, J., Reid, R., Rittmann, B.E., Lee, H.S. 2015. Contribution of Liquid/Gas Mass-Transfer Limitations to Dissolved Methane Oversaturation in Anaerobic Treatment of Dilute Wastewater. Environ. Sci. Technol., 49(17), 10366-10372.

[83]Yuan, H., Zhu, N. 2016. Progress in inhibition mechanisms and process control of intermediates and by-products in sewage sludge anaerobic digestion. Renew. Sust. Energ. Rev., 58, 429-438.

[84]Yuan, Z., Pratt, S., Batstone, D.J. 2012. Phosphorus recovery from wastewater through microbial processes. Curr. Opin. Biotechnol., 23(6), 878-883.

[85]Yue, X., Koh, Y.K., Ng, H.Y. 2015. Effects of dissolved organic matters (DOMs) on membrane fouling in anaerobic ceramic membrane bioreactors (AnCMBRs) treating domestic wastewater. Water Res., 86, 96-107. 
[86]Zayen, A., Mnif, S., Aloui, F., Fki, F., Loukil, S., Bouaziz, M., Sayadi, S. 2010. Anaerobic membrane bioreactor for the treatment of leachates from Jebel Chakir discharge in Tunisia. J. Hazard Mater., 177(1-3), 918-23. 